\title{
SEM Analysis of Enamel Abrasion after Air Polishing Treatment with Erythritol, Glycine and Sodium Bicarbonate
}

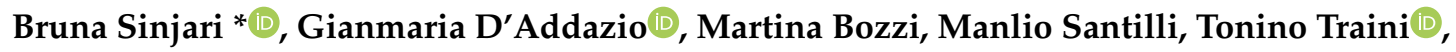 \\ Giovanna Murmura and Sergio Caputi \\ Department of Medical Oral and Biotechnological Sciences, University “G. d'Annunzio" of Chieti-Pescara, \\ Via dei Vestini 31, 66100 Chieti (CH), Italy \\ * Correspondence: b.sinjari@unich.it; Tel.: +39-39-27471479; Fax: +39-0871-3554070
}

Received: 30 June 2019; Accepted: 22 August 2019; Published: 27 August 2019

\begin{abstract}
The aim of this in vitro study was to evaluate the enamel surface topography after treatment with three air polishing powders: Glycine (A), erythritol (B), and sodium bicarbonate (C) (Air Flow Soft, Plus and Classic powders, EMS Electro Medical Systems S.A., Nyon, Switzerland). Fifteen extracted incisors were randomly divided into three groups of five teeth each, A, B and C, respectively. The teeth were blocked in plaster bases, washed, dried and half-covered with polytetrafluoroethylene strips before treatment. In this way, each half-treated dental element became test and control of itself. Comparative statistical analysis of $R_{\mathrm{q}}$ (geometric average of the deviations occurring in roughness profile) was performed. The scanning electron microscope (SEM) analysis showed different degrees of surface roughness between the groups, decreasing after treatment. In addition, a statistically significant reduction $p<0.05$ was present in group $C\left(R_{\mathrm{q}}\right.$ mean non-treated $108.17 \mu \mathrm{m}, 95 \% \mathrm{CI}$ : 97.29-124.01 and $R_{\mathrm{q}}$ mean treated $86.78 \mu \mathrm{m}, 95 \% \mathrm{CI}$ : 80.63-93.70). A decrease in surface roughness post-treatment was not observed in group A and B. Therefore, it may be concluded that the air flow powders tested herein can be used on dental enamel to reduce the surface roughness due to function and the action of dental therapies.
\end{abstract}

Keywords: enamel surface; surface topography; air-polishing powders; in vitro

\section{Introduction}

Over the years, the interest of the population and sensitization by dentists allowed to an increasing interest regarding professional oral hygiene, oral care habits and maintenance programs $[1,2]$. The goal was to improve the oral health of the population through the removal of subgingival and supragingival deposits, aimed at the deterioration of the oral biofilm [3]. It included the possibility of removing extrinsic stain and deposits from the tooth surface [4].

Moreover, biofilm is present as a multilayer microbial community organized to protect bacterial population from attacks by the host's immune defense system and from mouthwash rinses or antibiotic therapy $[5,6]$.

The conventional methods of professional teeth cleaning (removing biofilm, calculus and stain from tooth and root) are ultrasonic and sonic handpieces, rubber cups, prophylaxis paste, and the use of air polishing procedure [4]. Moreover, at the end of orthodontic treatments and following the removal of orthodontic brackets, it may be necessary to perform a debridement of composite used for adhesion and then an accurate cleaning to restore the natural roughness of the enamel [7]. Over the years, air polishing has been used for both stain removal and periodontal and peri-implant maintenance [8-10]. Dr. Robert Black introduced the air polishing system over 50 years ago [11]. This system involved the 
use of a compressed air spray combined with water and an abrasive agent [9]. During these years, its efficacy has been extensively studied through in vitro and in vivo studies $[4,10,12-15]$. To date, it is known that the kinetic energy developed by the hand piece that sends air, water and powder is able to remove stains and biofilms from different surfaces $[4,16]$. Although it is effective, the potential damage on the implant or restoration surfaces is still being studied [16]. Parameters such as particle size, type of powder and pressure may have different influences on the treatment outcome and possible side effects like tissue damage [4,16-18]. Different types of powders have been tested and used. At the beginning, sodium bicarbonate-based powders have been used as abrasive agents for air polishing procedures. The formulation of sodium bicarbonate powder is tribasic, free-flowing, food grade, and contains calcium carbonate and scant amounts of silica. Bicarbonate showed particles up to $250 \mu \mathrm{m}$. Its efficacy in removing deposits and stains was demonstrated when compared to conventional methods like manual scaling and rubber cup polishing. Bicarbonate-caused damages on dentin, cementum and restorative materials have been shown [14-16]. New formulations and new powders such as glycine, sodium calcium pyrophosphate and others have been proposed during the years. Unfortunately, there are no common standardized formulation and each brand uses its own protocol. Generally, it has been shown that the use of more soft powders reduces their negative effects. Glycine, a natural, water-soluble amino acid which presents a particle size of about $63 \mu \mathrm{m}$ has been shown to reduce the surface damage on restorative materials more than sodium bicarbonate [16]. It has also been reported to have better results on root surface, in terms of surface damage and plaque reduction compared to sodium bicarbonate [19]. More recently, an erythritol-based powder was developed and used for the same purposes [20]. The effects were evaluated by comparing erythritol with glycine and sodium bicarbonate, demonstrating less harmful effects on dentin in in vitro tests $[18,20]$. Erythritol is a sugar alcohol (polyol), non-toxic, chemically neutral and water-soluble agent [21]. It has been extensively used for subgingival air polishing because of its small particle size (about $14 \mu \mathrm{m}$ ), chemical properties, and positive effect against Porphyromonas gingivalis. In subgingival biofilms removal, the use of erythritol has been also shown to be more comfortable and to reduce the treatment time [22].

To the authors' best knowledge, there are no studies that compares the three abovementioned powders on enamel surface effects. Thus, the aim of this study was to compare the abrasion of three different powders such as erythritol, glycine and sodium bicarbonate on the dental enamel surface of extracted teeth in vitro.

The null hypothesis assumes that the roughness mean difference of human teeth enamel, between the paired samples (test and control) is zero, notwithstanding the type of powder used.

\section{Material and Methods}

\subsection{Study Sample}

The present study evaluated the difference between three different air polish powders on dental enamel surface topography.

A total of 15 anterior teeth were extracted for periodontal reasons from 15 different patients. The patients were all treated at the dental clinic of the Department of Medical, Oral and Biotechnological Sciences, University of Chieti-Pescara, Chieti, Italy. All the teeth were upper right or left central incisors and were free of filling materials. The study was approved on 21/03/2019 nr.6 by the Inter Institutional Ethics Committee of "G. d'Annunzio" University of Chieti-Pescara, Chieti, Italy. All patients gave a written informed consent to the treatment and study recruiting.

\subsection{Interventions}

After extractions, the patients were informed that their teeth would have been used for an in vitro study. The dental elements were washed in running water, disinfected and stored in distilled water. The teeth were randomly divided into 3 groups of 5 teeth per group. Teeth were sectioned at the cementoenamel junction (CEJ) level and only the crowns were used for the study. The teeth of each 
group were blocked in plaster bases, washed, dried and half-covered with polytetrafluoroethylene strips before carrying out the air polishing procedures. In this way, each half-treated dental element became test and control of itself. The groups were treated with three different powders (glycine, erythritol and sodium bicarbonate) using air-flow and were divided as follows:

- Group A treated with glycine (Air Flow Soft powder, EMS Electro Medical System S.A., Nyon, Switzerland). The powder had a particle size of about $65 \mu \mathrm{m}$;

- Group B treated with erythritol (Air Flow Plus powder, EMS Electro Medical System S.A., Nyon, Switzerland). The powder had a particle size of about $14 \mu \mathrm{m}$;

- Group C treated with sodium bicarbonate (Air Flow Classic powder, EMS Electro Medical System S.A., Nyon, Switzerland). The powder had a particle size of about $65 \mu \mathrm{m}$.

The teeth of each group were treated with the respective powder by air-flow (Airflow Handy 3.0 EMS Electro Medical System S.A., Nylon, Switzerland) for about $10 \mathrm{~s}$ at a distance of about $1 \mathrm{~cm}$ with horizontal movements, perpendicular to the tooth surface, as recommended by the manufacturer. Pressure conditions recommended by the producer (air pressure: $2.7-3.5$ bar; water pressure: 1.0-2.2 bar) were applied in all groups during the experiments. The dental elements were then removed from the plaster, sonicated in distilled water for $20 \mathrm{~min}$ and processed for SEM analysis according to the procedure discussed above [23]. Three random fields were chosen, avoiding enamel microcracks caused by sample preparation for microscope analysis. Each field had an area of $135.7 \mu \mathrm{m}^{2}$.

\subsection{Variables Measured}

Briefly, the surface morphology of each tooth was examined using a scanning electron microscope (Evo 50, Carl Zeiss, Oberkochen, Germany).

Samples were metallized by a gold-sputter Emitech K550 (Emitech Ltd., Ashford, UK) and subsequently inserted into the sample-holder for SEM analysis. The images obtained by SEM were then transported and analyzed using ImageJ software 1.48f 3D (Wayne Rasband at NIH), in order to highlight the incongruity of the surface in every sample, through the system of graphs with levels of roughness, then a 3D faithful image reconstruction of the same was collected and analyzed.

Profilometer measurements through $R_{\mathrm{q}}$ : Geometric average of the deviations occurring in roughness profile were also performed.

\subsection{Statistical Analysis}

Statistical analysis was performed through paired sample t-test. All values were considered significant for $p<0.05$. To evaluate the paired differences in $R_{\mathrm{q}}$ of the three groups the SPSS rel. 21.00 software (IBM, Armonk, NY, USA) was used. The normality test (Kolmogorov-Smirnov) was used to verify that the data were normally distributed. Methodology and statistical analysis were reviewed by an independent statistician.

\section{Results}

15 samples divided into three groups were treated and analysed by SEM analysis. Each sample was analysed in one half side as a control, without performing any type of treatment and in the other side as a test following surface treatment with air polish with three different powders.

The SEM investigation showed a difference on enamel surface roughness following the three different treatments carried out. The SEM images clearly demonstrated the reduction of the surface roughness by comparing the surfaces under examination before and after treatment (Figures 1-3). In fact, it is well recognizable on SEM images (Figures 1 and 3) how the surface became more plain after treatment. In Table 1, the average surface roughness is reported, divided into three groups, and for test and for control sides. These comparative values showed a reduction in roughness in all the groups, although with differences between the groups. Analyzing the individual treatments, a statistically significant reduction $p<0.05$ was present in the group C, treated with bicarbonate (Table 1, Figure 4). 
Likewise, a reduction was also noted in the remaining two groups, albeit not in a statistically significant way. Thus, the null hypothesis was partially rejected.

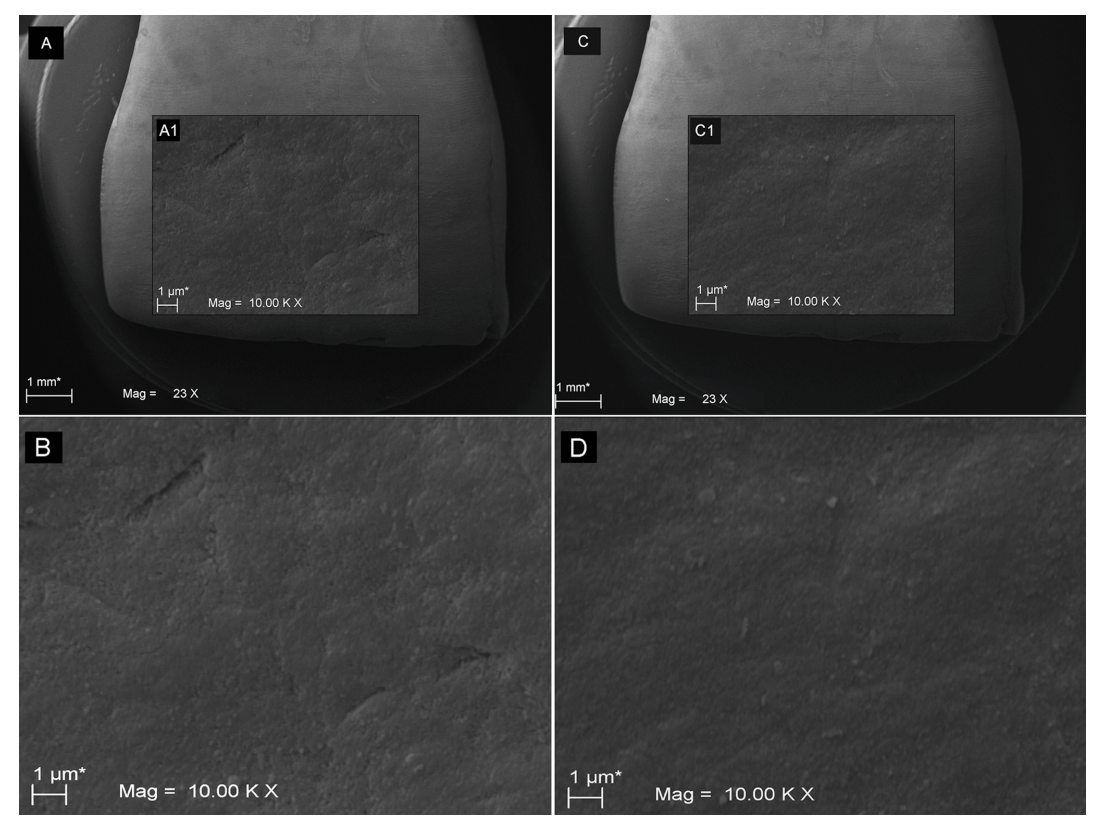

Figure 1. SEM images showing the human enamel surface alterations before and after the glycine powder use (group A). The images show a lot of enamel irregularities: (A) $23 \times$ magnification image of non-treated half part of tooth; (B, magnification of A1 in A) higher magnification $(10,000 \times)$ of non-treated enamel. Meanwhile, the (C) $23 \times$ and (D, magnification of $\mathbf{C 1}$ in $\mathbf{C}) 10,000 \times$ demonstrate the enamel surface after treatment showing a reduction of enamel irregularities.
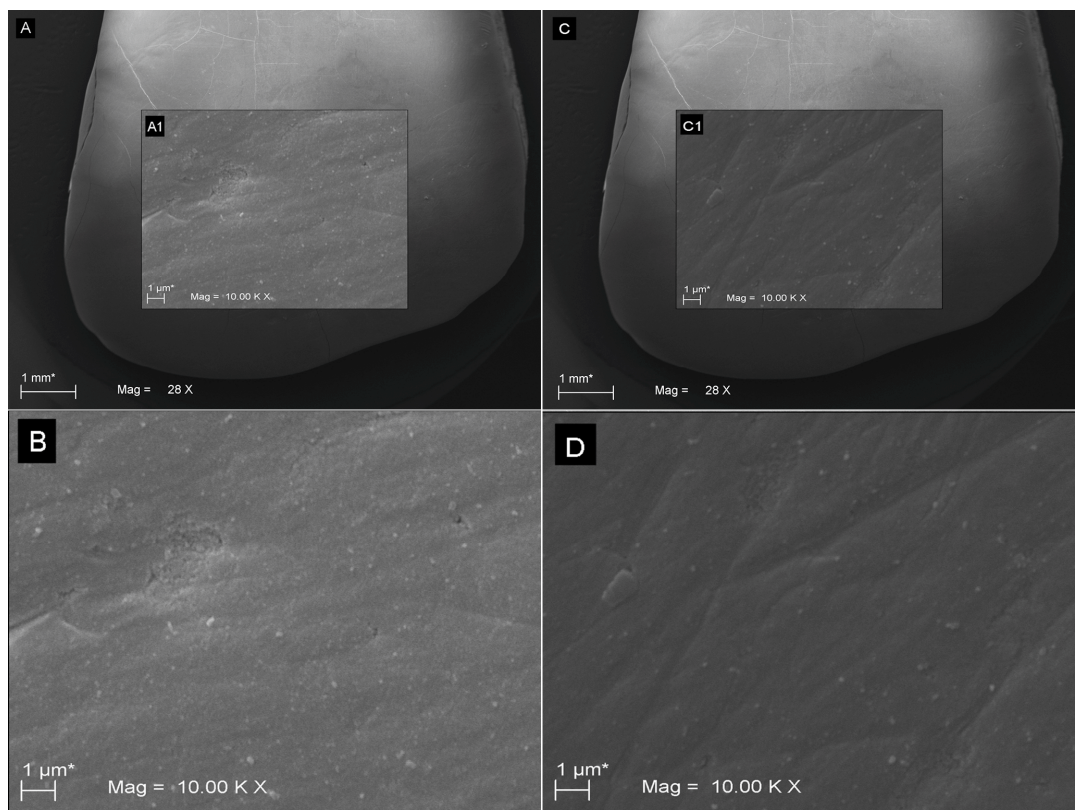

Figure 2. SEM images showing the human enamel surface alterations before and after the erythritol powder use (group B). The images show a lot of enamel irregularities: (A) $23 \times$ magnification image of non-treated half part of tooth; (B, magnification of $\mathbf{A 1}$ in A) higher magnification $(10,000 \times)$ of non-treated enamel. Meanwhile, the (C) $23 \times$ and (D, magnification of $\mathbf{C} \mathbf{1}$ in $\mathbf{C}) 10,000 \times$ demonstrate the enamel surface after treatment showing a reduction of enamel irregularities. However, a lot of surface depressions or grooves were also present. 

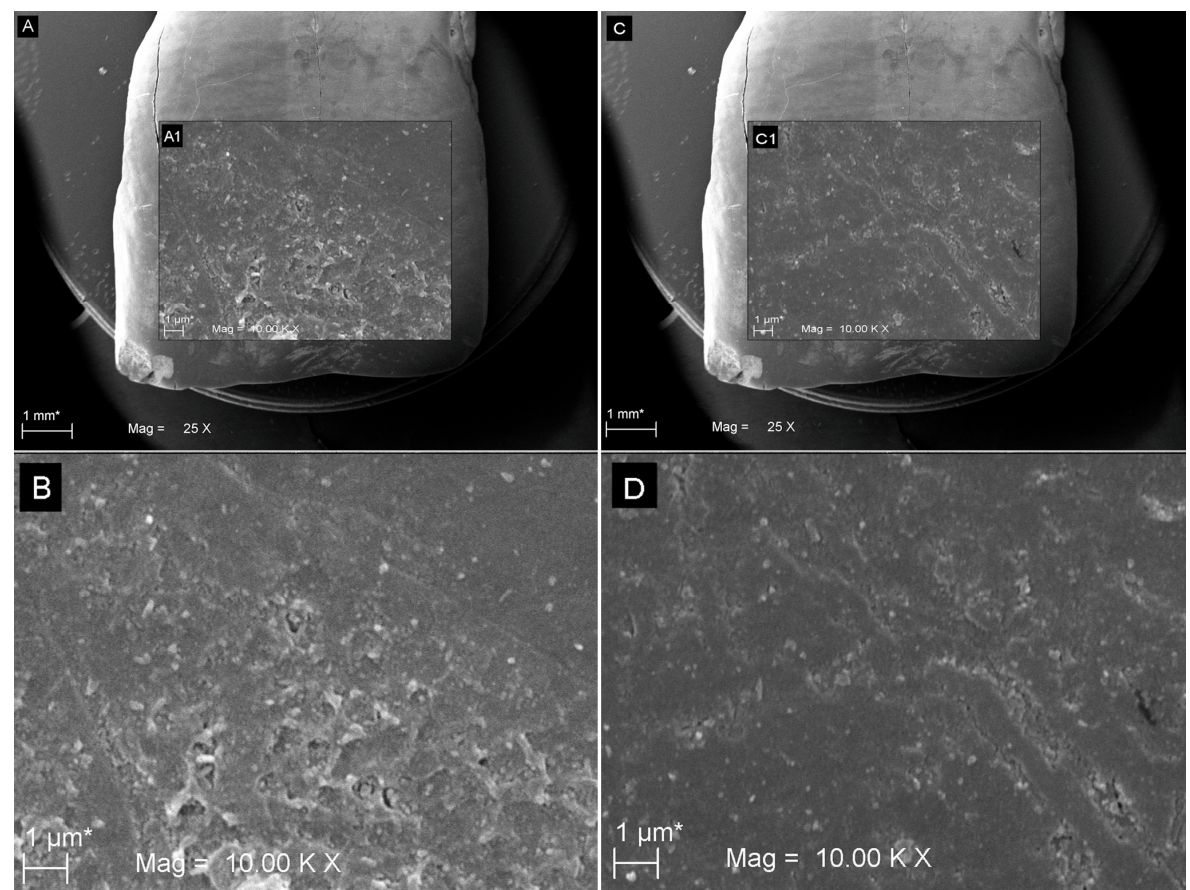

Figure 3. SEM images showing the human enamel surface alterations before and after the bicarbonate powder use (group C). The images show numerous enamel irregularities: (A) $23 \times$ magnification image of non-treated half part of tooth; (B, magnification of $\mathbf{A 1}$ in A) higher magnification $(10,000 \times)$ of non-treated enamel. Pronounced depressions were present on enamel specimens. Meanwhile, the (C) $23 \times$ and (D, magnification of $\mathbf{C 1}$ in C) $10,000 \times$ demonstrate the enamel surface after treatment showing a reduction of enamel irregularities. Irregularities were also present but the major reduction was calculated on the specimens treated with this powder $(p<0.05)$.

Table 1. Surface roughness $\left(R_{\mathrm{q}}\right)$ measurements in control and treatment samples. Samples showed a statistically significant difference only in group $C$ (sodium bicarbonate) $(p<0.05)$. Paired t-test was performed to verify the significance of the difference between groups.

\begin{tabular}{|c|c|c|c|c|c|c|c|c|c|}
\hline \multicolumn{10}{|c|}{ Paired Samples Statistics (T test) } \\
\hline & Groups & Mean & \multicolumn{2}{|c|}{$\mathbf{N}$} & \multicolumn{2}{|c|}{ Std. Deviation } & \multicolumn{3}{|c|}{ Std. Error Mean } \\
\hline \multirow[b]{2}{*}{$\mathrm{A}$} & gly_control & 69.7100 & \multicolumn{2}{|c|}{5} & \multicolumn{2}{|c|}{30.38000} & \multicolumn{3}{|c|}{13.58635} \\
\hline & gly_treatment & 52.1200 & \multicolumn{2}{|c|}{5} & \multicolumn{2}{|c|}{14.39000} & \multicolumn{3}{|c|}{6.43540} \\
\hline \multirow{2}{*}{$\mathrm{B}$} & eryt_control & 96.6600 & \multirow{2}{*}{\multicolumn{2}{|c|}{$\begin{array}{l}5 \\
5\end{array}$}} & & \multicolumn{3}{|c|}{13.50585} \\
\hline & eryt_treatment & 90.6800 & & & \multicolumn{2}{|c|}{8.93000} & \multicolumn{3}{|c|}{3.99362} \\
\hline \multirow{2}{*}{$\mathrm{C}$} & sodbi_control & 108.1700 & \multirow{2}{*}{\multicolumn{2}{|c|}{$\begin{array}{l}5 \\
5\end{array}$}} & \multirow{2}{*}{\multicolumn{2}{|c|}{$\begin{array}{c}16.70000 \\
7.92000\end{array}$}} & \multirow{2}{*}{\multicolumn{3}{|c|}{$\begin{array}{l}7.46847 \\
3.54193\end{array}$}} \\
\hline & sodbi_treatment & 86.7800 & & & & & & & \\
\hline & \multirow{3}{*}{ Groups } & \multicolumn{5}{|c|}{ Paired Differences } & \multirow{3}{*}{$\mathbf{t}$} & \multirow{3}{*}{ df } & \multirow{3}{*}{$\begin{array}{c}\text { Sig. } \\
\text { (2-tailed) }\end{array}$} \\
\hline & & \multirow{2}{*}{ Mean } & \multirow{2}{*}{$\begin{array}{c}\text { Std. } \\
\text { Deviation }\end{array}$} & \multirow{2}{*}{$\begin{array}{l}\text { Std. Error } \\
\text { Mean }\end{array}$} & \multicolumn{2}{|c|}{$\begin{array}{l}95 \% \text { Confidence Interval } \\
\text { of the Difference }\end{array}$} & & & \\
\hline & & & & & Lower & Upper & & & \\
\hline $\mathrm{A}$ & $\begin{array}{l}\text { gly_control } \\
\text { gly_treatment }\end{array}$ & 17.59000 & 15.99000 & 7.15095 & -2.26421 & 37.44421 & 2.460 & 4 & 0.070 \\
\hline $\mathrm{B}$ & $\begin{array}{l}\text { gly_control } \\
\text { gly_treatment }\end{array}$ & 5.98000 & 21.27000 & 9.51223 & -20.43019 & 32.39019 & 0.629 & 4 & 0.564 \\
\hline $\mathrm{C}$ & $\begin{array}{l}\text { sodbi_control } \\
\text { sodbi_treatment }\end{array}$ & 21.39000 & 8.78000 & 3.92654 & 10.48819 & 32.29181 & 5.448 & 4 & 0.006 \\
\hline
\end{tabular}




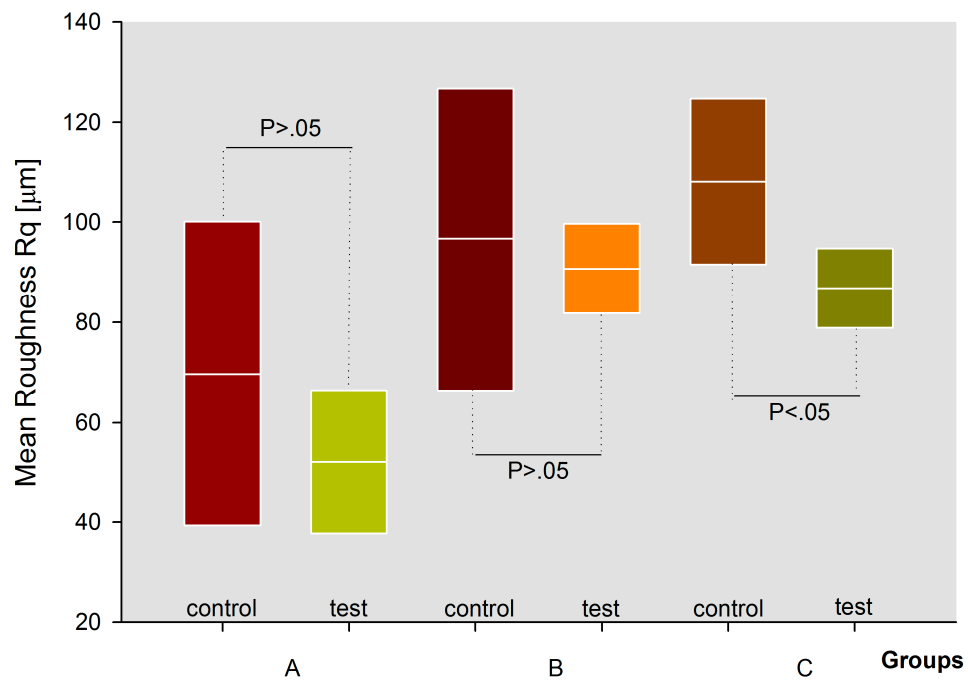

Figure 4. Graphical representation of roughness means of control and test surfaces after treatments with A (glycine), B (erythritol) and C (sodium bicarbonate). The roughness change was significant different for group $\mathrm{C}(p<0.05)$.

These results were also confirmed by 3D profilometrric analysis, which showed a 3D graphic reconstruction of the different surface roughnesses in the three groups, as demonstrated in Figure 5.
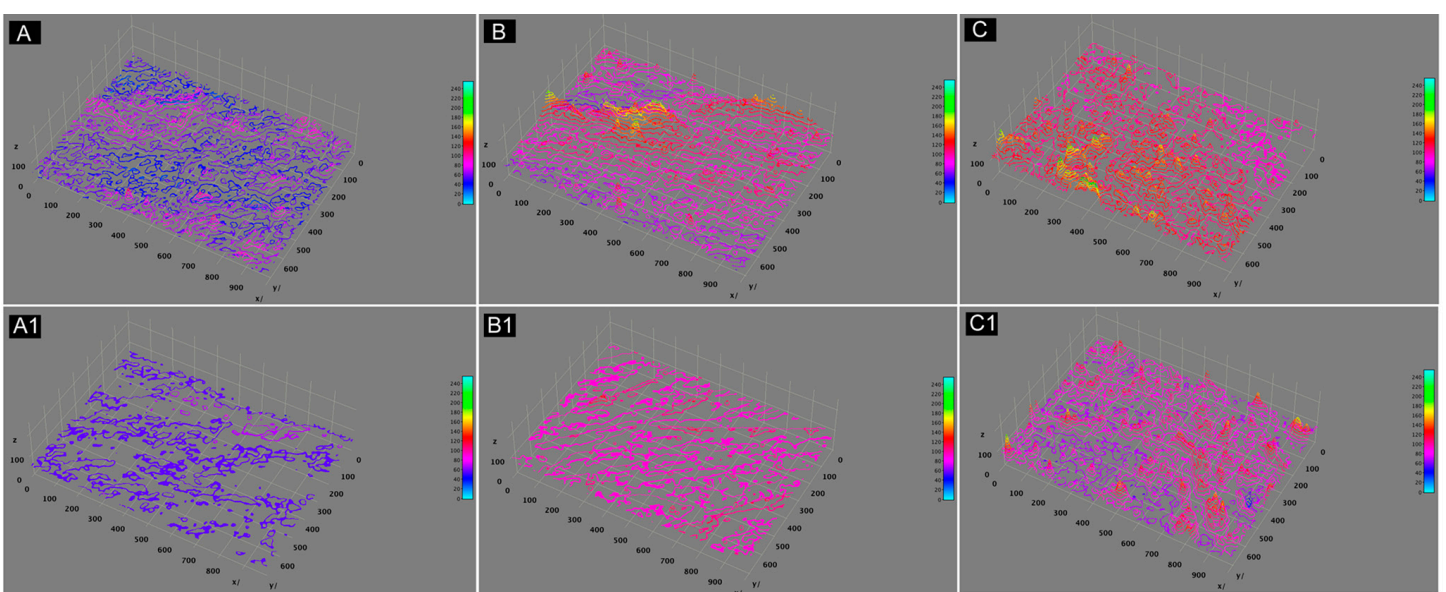

Figure 5. (A,A1) show the 3D analysis of the surface roughness and its reduction in group A (glycine), non treated in image (A) and treated in image (A1). (B,B1) show the 3D analysis of the surface roughness and its reduction in group B (erythritol), non treated in (B) and treated in (B1). (C,C1) show the 3D analysis of the surface roughness and its reduction in group $\mathrm{C}$ (sodium bicarbonate), non treated in (C) and treated in (C1).

\section{Discussion}

The objective of the study was to evaluate the effects on enamel surface topography, in terms of surface roughness, of three different commercially available powders using an air polishing system. It is important to remember that the data were obtained under standardized working conditions. Time, level of dehydration, surface cleaning, storage and processing methods were the same, meanwhile, the type of powder used was different.

Many studies have shown that the polishing process is a necessary step in order to reduce the surface roughness resulting from the scaling and root planning process [24-26]. In this regard, it was decided to test erythritol, glycine and sodium bicarbonate powders on enamel. Moreover, it has been shown that air polishing is the most effective polishing method in terms of reducing time and costs [26]. 
Our samples have all shown a clear reduction in surface roughness following treatment. In fact, SEM images allowed an excellent visual of the effects of various powders after treatment. Furthermore, the images were supported by 3D analysis which showed roughness reduction in all the examined samples (Figure 5). The obtained data demonstrated a lower roughness reduction rate in the samples of group B, treated with erythritol than the other two groups. Probably, these values can be justified by the lowest particle size that this powder has.

Müller et al. (2014) [20] have shown that erythritol used in the treatment of $>4 \mathrm{~mm}$ pockets can be a safety and reliable method in order to reduce it. The results of this treatment were comparable to the results of the classic treatment with sonic instruments. It was also demonstrated by authors to be less painful and more comfortable for the patient [20]. Authors concluded that the erythritol powder, having a reduced granulometry, may be more suitable for subgingival treatments [20]. Although, we did not analyze the safety and the subgingival effects of the three powders, our results demonstrated there were no statistically significant differences in terms of surface roughness reduction in the samples treated with erythritol. On the other hand, glycine and bicarbonate powders were more effective in reducing surface roughness on human enamel. From a statistical point of view, bicarbonate was the only one able to guarantee an effective and statistically significant superficial roughness reduction on the present study.

Moreover, our results can be better explained, if we take into consideration the results after thoroughly investigating the particle size using SEM.

The particles size of bicarbonate (group C) were reported by the manufacturing company to be the same of glycine (group A). Instead, SEM evaluation (please see supplementary material) shown that the group $C$ powder has different size particles (some reaching almost $160 \mu \mathrm{m}$ ). For these reasons it is clear that the bicarbonate particles allowed to obtain different results comparing to glycine, despite the equal granulometry declared by the manufacturer. In any case, different studies have shown larger-sized particles in sodium bicarbonate powders. Petersilka in 2011 [9] showed how the sodium bicarbonate particles, from the same manufacturer tested, reached particle sizes up to $250 \mu \mathrm{m}$. These results, according to the data obtained in this study, could justify the obtained effect on the surface roughness. Similarly, studies in literature showed that powders with reduced grain sizes, like glycine, were more effective on different surfaces such as dentin or composite resins [15], or like erythritol in subgingival treatment [20].

Barnes et al. in 2014 [15] tested different powders produced by different manufacturing companies, finding statistically significant differences in terms of roughness on hard tissues using the same powder but produced by different companies. Instead, we analysed the effects of three different powders produced by the same company on the enamel surface of extracted upper incisors.

Karacaoglu et al. in 2016 [26] evaluated the reduction of surface roughness comparing three different types of treatment: rubber cup, air polishing and a new method with stain buster bur. This new system was evaluated as the most effective in reducing enamel roughness, comparable to the results obtained with prophylaxis paste. Air polishing obtained the worst results measured by $R_{\mathrm{q}}$. In this study, however, treatment with air polishing was performed with Clinpro Prophy Glycine Powder. As mentioned before, each company has different formulations that can provide different results. Specifically, glycine powder with reduced particle size was used by the authors. Meanwhile, the values obtained in our study using sodium bicarbonate, glycine and erythritol were more satisfactory in terms of $R_{\mathrm{q}}$ for the groups treated with bicarbonate than the other two.

Barnes et al. in 2014 [15] evaluated the effects of different powders on enamel, hybrid composites and resin modified glass ionomer cements. In this study glycine and bicarbonate powders were the most effective and at the same time the less harmful to these surfaces. In the Barnes et al. study [15], however, enamel from non-erupted third molar was used. Whilst, in the present study, erupted teeth that had already undergone the effects of function within the oral cavity, as well as previous dental procedures like scaling and root planning, were used. For this reason, the results presented herein may be probably more realistic to a routine clinical use of air polishing powders. 
In 2016, Camboni et al. [27] evaluated the surface of the enamel following treatment with airflow and with prophylaxis pastes demonstrating how the air-flow could be less harmful to the tooth hard tissues compared to the prophylaxis pastes which resulted in being able to abrade the enamel surface, to flatten it, and deposit debris into the microcavities [17]. In agreement with this study, our SEM images demonstrated how the enamel surface flatten after treatment, although we did not evaluate the safety of treatment with these powders.

With regard to potential harmful effects, the results have been evaluated in relation to dental enamel, finding a real benefit following the air flow treatment. Buhler et al. in 2015 published a review concerning the effects of air polishing on hard and soft periodontal tissues. The authors concluded that air flow can also be used safely on dentin, root cement and many tissues [16].

A limitation of the present study was the small sample size as only 15 central upper incisors were evaluated. Other studies such as Karacaoglu et al. in 2016 [26] evaluated a bigger sample size (60 teeth) taking into consideration only glycine powder. Moreover, we only analyzed three types of airflow powders. Further investigation should be performed to overcome the present limitations. In addition, other interesting analysis should be performed on the effects of the abovementioned air powders on the enamel after de-bonding procedures and the safety effects of the treatment with these three powders.

Therefore, our data allow us to conclude that the air flow powders tested in the present study can be used on dental enamel to reduce surface roughness due to daily function and the action of dental therapies. Moreover, in addition to identifying the effects of individual powders, the effects of same powder produced by different companies should be thoroughly investigated. Generally, dentists and hygienists for a better clinical performance should know the various formulations and the correct use protocols to be able to benefit from the various possible treatments with airflow. However, the limitations of in-vitro studies should be considered in interpreting the present findings.

Supplementary Materials: The following are available online at http://www.mdpi.com/2079-6412/9/9/549/s1.

Author Contributions: Conceptualization, B.S. and S.C.; Methodology, M.B.; Software, T.T. and M.S.; Validation, T.T., B.S. and G.D.; Formal Analysis, G.M.; Investigation, B.S. and G.D.; Resources, G.M. and S.C.; Data Curation, M.S., M.B. and G.D.; Writing-Original Draft Preparation, B.S. and G.D.; Writing-Review and Editing, T.T. and M.S.; Visualization, G.M.; Supervision, S.C.; Project Administration, B.S.; Funding Acquisition, S.C.

Funding: This research received no external funding.

Conflicts of Interest: The authors declare no conflicts of interest.

\section{References}

1. WHO Expert Committee. Prevention Methods and Programs for Oral Diseases; Technical Report, Series 713; World Health Organization: Geneva, Switzerland, 1984.

2. Axelsson, P.; Nyström, B.; Lindhe, J. The long-term effect of a plaque control program on tooth mortality, caries and periodontal disease in adults: Results after 30 years of maintenance. J. Clin. Periodontol. 2004, 31, 749-757. [CrossRef] [PubMed]

3. Lang, N.P.; Tonetti, M.S. Periodontal risk assessment (PRA) for patients in supportive periodontal therapy (SPT). Oral Health Prev. Dent. 2003, 1, 7-16. [PubMed]

4. Graumann, S.J.; Sensat, M.L.; Stoltenberg, J.L. Air polishing: A review of current literature. J. Dent. Hyg. 2013, 87, 173-180. [PubMed]

5. Fux, C.A.; Stoodley, P.; Hall-Stoodley, L.; Costerton, J.W. Bacterial bio-films: A diagnostic and therapeutic challenge. Expert Rev. Anti Infect. Ther. 2003, 1, 667-683. [CrossRef] [PubMed]

6. Socransky, S.S.; Haffajee, A.D. Dental biofilms: Difficult therapeutic targets. Periodontol. 2000 2002, 28, 12-55. [CrossRef] [PubMed]

7. Eslamian, L.; Borzabadi-Farahani, A.; Tavakol, P.; Tavakol, A.; Amini, N.; Lynch, E. Effect of multiple debonding sequences on shear bond strength of new stainless steel brackets. J. Orthod. Sci. 2015, 4, 37-41. [PubMed] 
8. Sculean, A.; Bastendorf, K.D.; Becker, C.; Bush, B.; Einwag, J.; Lanoway, C.; Platzer, U.; Schmage, P.; Schoeneich, B.; Walter, C.; et al. A paradigm shift in mechanical biofilm management? Subgingival air polishing: A new way to improve mechanical biofilm management in the dental practice. Quintessence Int. 2013, 44, 475-477. [PubMed]

9. Petersilka, G.J. Subgingival air-polishing in the treatment of periodontal biofilm infections. Periodontol. 2000 2011, 55, 124-142. [CrossRef]

10. Wennstrom, J.L.; Dahlen, G.; Ramberg, P. Subgingival debridement of periodontal pockets by air polishing in comparison with ultrasonic instrumentation during maintenance therapy. J. Clin. Periodontol. 2011, 38, 820-827. [CrossRef]

11. Black, R.B. Air polishing: Some fundamentals. J. Am. Dent. Assoc. 1950, 41, 701-710. [CrossRef]

12. Johnson, W.W.; Barnes, C.M.; Covey, D.A.; Walker, M.P.; Ross, J.A. An in vitro investigation of the effects of an aluminum air polishing powder delivered via the Prophy Jet ${ }^{\mathrm{TM}}$ on dental restorative materials. J. Prosthodont. 2004, 13, 1-7. [CrossRef] [PubMed]

13. Schmage, P.; Kahili, F.; Nergiz, I.; Scorziello, T.M.; Platzer, U.; Pfeiffer, P. Cleaning effectiveness of implant prophylaxis instruments. Int. J. Oral Maxillofac. Implants 2014, 29, 331-337. [CrossRef] [PubMed]

14. Louropoulou, A.; Slot, D.E.; Van der Weijden, F. Influence of mechanical instruments on the biocompatibility of titanium dental implants surfaces: A systematic review. Clin. Oral Implant Res. 2015, 26, 841-850. [CrossRef] [PubMed]

15. Barnes, C.M.; Covey, D.; Watanabe, H.; Simetich, B.; Schulte, J.R.; Chen, H. An in vitro comparison of the effects of various air polishing powders on enamel and selected aesthetic restorative materials. J. Clin. Dent. 2014, 25, 76-87. [PubMed]

16. Bühler, J.; Amato, M.; Weiger, R.; Walter, C. A systematic review on the effects of air polishing devices on oral tissues. Int. J. Dent. Hyg. 2016, 14, 15-28. [CrossRef] [PubMed]

17. Jost-Brinkmann, P.G. The influence of air polishers on tooth enamel. An in-vitro study. J. Orofac. Orthop. 1998, 59, 1-16. [CrossRef] [PubMed]

18. Tada, K.; Kakuta, K.; Ogura, H.; Sato, S. Effect of particle diameter on air polishing of dentin surfaces. Odontology 2010, 98, 31-36. [CrossRef]

19. Bühler, J.; Schmidli, F.; Weiger, R.; Walter, C. Analysis of the effects of air polishing powders containing sodium bicarbonate and glycine on human teeth. Clin. Oral Investig. 2015, 19, 877-885. [CrossRef]

20. Müller, N.; Moëne, R.; Cancela, J.A.; Mombelli, A. Subgingival air-polishing with erythritol during periodontal maintenance: Randomized clinical trial of twelve months. J. Clin. Periodontol. 2014, 41, 883-889. [CrossRef]

21. Munro, I.C.; Berndt, W.O.; Borzelleca, J.F.; Flamm, G.; Lynch, B.S.; Kennepohl, E.; Bar, E.A.; Modderman, J. Erythritol: An interpretive summary of biochemical, metabolic, toxicological and clinical data. Food Chem. Toxicol. 1998, 36, 1139-1174. [CrossRef]

22. Park, E.J.; Kwon, E.Y.; Kim, H.J.; Lee, J.Y.; Choi, J.; Joo, J.Y. Clinical and microbiological effects of the supplementary use of an erythritol powder air-polishing device in non-surgical periodontal therapy: A randomized clinical trial. J. Periodontal Implant Sci. 2018, 48, 295-304. [CrossRef] [PubMed]

23. Sinjari, B.; D'Addazio, G.; Bozzi, M.; Celletti, R.; Traini, T.; Mavriqi, L.; Caputi, S. Comparison of a novel ultrasonic scaler tip vs. conventional design on a titanium surface. Material 2018, 11, 2345. [CrossRef] [PubMed]

24. Weaks, L.M.; Lescher, N.B.; Barnes, C.M.; Holroyd, S.V. Clinical evaluation of the Prophy-Jet as an instrument for routine removal of tooth stain and plaque. J. Periodontol. 1984, 55, 486-488. [CrossRef] [PubMed]

25. Kontturi-Närki, V.; Markkanen, S.; Markkanen, H. Effects of air polishing on dental plaque removal and hard tissue as evaluated by scanning electron microscopy. J. Periodontol. 1990, 61, 334-338. [CrossRef] [PubMed]

26. Karacaoglu, F.; Tuzcel, N.Y.; Akkaya, M. A comperative evaluation of 3 different polishing methods on tooth surface roughness. J. Biomed. Sci. 2016, 6, 1-6. [CrossRef]

27. Camboni, S.; Donnet, M. Tooth surface comparison after air polishing and rubber cup: A scanning electron microscopy study. J. Clin. Dent. 2016, 27, 13-18. [PubMed]

(C) 2019 by the authors. Licensee MDPI, Basel, Switzerland. This article is an open access article distributed under the terms and conditions of the Creative Commons Attribution (CC BY) license (http://creativecommons.org/licenses/by/4.0/). 